\title{
Peran Implementasi Picture Archiving and Communication System dalam Pelayanan Radiologi di Rumah Sakit Premier Bintaro
}

\author{
Suandari, P. V. L*, I Putu Eka Juliantara*, Erni R. Rusmana ${ }^{* * *}$ \\ ${ }^{*}$ Universitas Bali Internasional \\ ${ }^{* *}$ AKTEK Radiodiagnostik dan Radioterapi Bali \\ ${ }^{* * *}$ RS Premier Bintaro \\ Email:vierdalya93@gmail.com,ekaj.atro@gmail.com,erni_yanrizal@yahoo.com
}

\begin{abstract}
Premier Bintaro Hospital is equipped with High-end modalities with various types of advanced radiological examinations. There are several service centers that require continuous imaging support, such as vascular centers, Pain Centers, Spine centers and others. Integrated storage and access to patient data is needed to improve work efficiency. With the implementation of Picture Archiving And Communication System (PACS) in Radiology Unit, there are improvements in services and increased productivity when compared to previous system. This research discussed a number of issues related to the role of PACS in Radiology services as evaluation material for services compared with the system before PACS was implemented. This research determined the role of PACS in Premier Bintaro Hospital. The application of PACS in Premier bintaro Hospital basically has the same workflow compared to workflows in general. Application of HL7 interface System which is equipped with DMWL makes PACS applied will integrated properly with HIS / RIS. The advantages of implementing PACS are more on data integration, storage, data editing, and presentation of data in digital form. The lack of PACS was more focused on the stability of the connection as the basis of the data transportation path needed. The challenge in the future was the problem of
\end{abstract}

strengthening the stability of connection and education to users related.

Keywords : PACS, HL7, Premier Bintaro Hospital

\section{PENDAHULUAN}

Semakin populernya penerapan sensor digital dalam ilmu kedokteran dan kesehatan, maka jumlah data digital yang dihasilkan di rumah sakit dan praktik medis semakin meningkat secara eksponensial. Selain penerapan teknologi digital seperti Computer Tomography (CT), pencitraan kedokteran nuklir atau Magnetic Resonance Imaging (MRI), teknologi analog sebelumnya seperti $\mathrm{X}$-ray menjadi mampu menghasilkan gambar digital, bukan film analog (CR dan DR). Untuk mendukung fungsi operasional dan fungsi administratif di dalam instalasi radiologi diperlukan sistem informasi terintegrasi dengan pemanfaatan PACS sebagai metode komunikasi terkomputerisasi yang mampu menyimpan data hasil citra medis radiologi.

Picture Archiving And Communication System (PACS) menyediakan metode penanganan yang efisien untuk pencitraan medis dan implementasinya dalam bentuk media lain, seperti materi audio dan film. PACS merupakan sistem yang berfungsi untuk menerima, menyimpan, menampilkan serta mendistribusikan gambar medis radiologi. Selama ini, efisiensi pelayanan radiologi dibatasi dengan penggunaan film, penanganan film, akan tetapi dengan 
penggunaan PACS, citra medis radiologi memungkinkan untuk dapat dilihat secara virtual dimana saja pada computer server atau melalui computer personal biasa. Saat ini PACS berkembang dari yang awalnya hanya untuk melayani instalasi radiologi di satu rumah sakit namun menjadi sistem yang mampu melayani kebutuhan data pencitraan di seluruh bagian rumah sakit. Beberapa instalasi yang maju terutama di luar negeri, PACS telah berkembang menjadi 'Multi Integrated Site' PACS.

PACS saat ini menyimpan, melanjutkan dan mengubah data medis di rumah sakit atau praktik medis. Akibatnya, PACS menjadikan data mudah diakses dari berbagai lokasi, tersedia dalam waktu lama, dan dapat diedit. Gambar dapat dilihat dan dibandingkan di workstation khusus, memberikan banyak keuntungan seperti melihat secara simultan di lokasi yang berbeda dan perangkat lunak grafis yang kuat. Ini mengarah pada percepatan proses medis terkait dan menghemat biaya. Pengembangan dilakukan kearah koneksi area luas yang lebih cepat (WAN) dan komunikasi nirkabel mengarahkan penelitian PACS ke arah teleradiologi, yaitu kerja sama radiografer dengan radiologist jarak jauh, misalnya melalui perangkat seluler dan rapid data transfer.

Rumah Sakit Premier Bintaro dilengkapi dengan modalitas High-end dengan berbagai jenis pemeriksaan radiologi lanjutan. Pada satu kali kunjungan pasien ke unit radiologi, terkadang pasien melakukan pemeriksaan penunjang menggunakan lebih dari satu modalitas yang ada. Selain itu di RS Premier Bintaro terdapat beberapa pusat pelayanan yang memerlukan imaging sebagai penunjang yang berkelanjutan, seperti vascular center, pain center, spine center dan lainnya. Sehingga penyimpanan dan akses data pasien yang mudah dan terintegrasi sangat diperlukan untuk meningkatkan efisiensi kerja.

Dengan diterapkannya PACS di Instalasi Radiologi RS Premier Bintaro, terdapat perbaikan pelayanan serta peningkatan produktifitas bila dibandingkan proses manual sebelum diterapkannya PACS. Tujuan penelitian ini untuk mengetahui evaluasi pemanfaatan PACS dalam pelayanan radiologi RS Premier Bintaro sehingga dapat dijadikan bahan evaluasi terkait pengembangan sistem ke tahap selanjutnya.

\section{METODE PENELITIAN}

Penelitian ini dibuat untuk mengetahui evaluasi pemanfaatan PACS dalam pelayanan radiologi RS Premier Bintaro. Panelitian ini disusun dengan kajian literatur, hasil observasi, serta dokumentasi di RS Premier Bintaro. Penjelasan PACS pada penelitian ini akan terkait peranan PACS di RS Premier Bintaro yang meliputi worklfow, kelebihan penggunaan PACS, kekurangan penggunaan PACS, serta permasalahan yang timbul akibat penerapan sistem tersebut. Desain penelitian ini menggunakan studi deskriptif observasional. Pada tahap pertama dilakukan identifikasi masalah secara berturut-turut yaitu (1) mengidentifikasi alur pelayanan radiologi, (2) melakukan wawancara dengan pemberi pelayanan, (3) melakukan focus group discussion, (4) mengidentifikasi dan menganalisa kelebihan dan kekurangan penerapan sistem, (5) menentukan akar masalah, (6) menyusun rekomendasi per tahap pelayanan dan (7) menyusun rencana tindak lanjut dari penerapan PACS. Sampel yang digunakan pada penelitian ini yaitu petugas radiologi, dokter radiolog dan dokter pengirim.

\section{HASIL DAN PEMBAHASAN}

Dalam penerapan sistem PACS di instalasi radiologi, diperlukan integrasi dari beberapa aspek yang terkait dalam sistem tersebut seperti : SIMRS atau RIS, modalitas (CT, MRI, C-Arm, CR, DR), serta aspek output (film printing, $C D$ Burner, remote Display dan lainnya).

\section{Workflow}

Dalam pengintegrasian seluruh aspek tersebut diperlukan workflow yang benar sehingga PACS dapat diterapkan secara optimal. Apabila dilihat dari workflow yang ada, PACS memiliki kemampuan yang lebih 
luas dalam hal jangkauan dan akses data baik dari segi tempat dan waktu. Workflow PACS secara sederhana dapat dilihat pada gambar 1 .

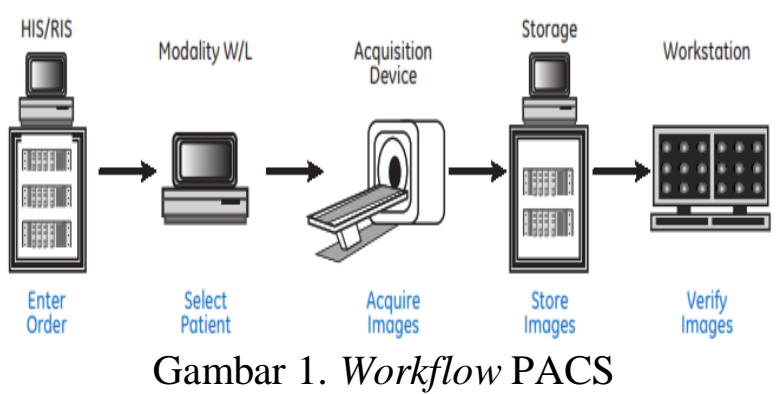

Pada gambar 1 dijelaskan bahwa alur kerja dalam instalasi radiologi dimana HIS/RIS bertanggungjawab dalam proses pemesanan jadwal pemeriksaan, kemudian mempersiapkan daftar kerja (modality) selanjutnya akan dilakukan proses akusisi pemeriksaan. PACS akan menjalankan perannya dalam proses penyimpanan dilakukan untuk optik medis atau media magnetik dengan menggunakan perangkat penyimpanan untuk jangka pandek ataupun jangka panjang, selanjutnya proses pengambilan serta pengiriman informasi klinis citra radiologi dalam bentuk digital.

Dengan workflow seperti diatas tentu membuat pelayanan radiologi jauh lebih efisien. Penerapan PACS di RS Premier Bintaro pada dasarnya memiliki workflow yang sama dibandingkan dengan workflow pada gambar 1. Dilihat dari kualitas sistem yang disajikan oleh PACS meliputi kemudahan untuk digunakan dan kemudahan untuk dipelajari sudah sangat baik, sedangkan bila dilihat dari segi keamanan sistem serta fleksibelitas PACS yang diintegrasikan dengan sistem lainnya mampu menambah performa pelayanan radiologi di RS Premier Bintaro. Keberhasilan penerapan PACS di RS Premier Bintaro tidak lepas dari ketersediaan Hospital Information System (HIS) yang sudah tersedia jauh sebelum implementasi PACS dilakukan. Dengan adanya HIS, akan mempermudah implementasi PACS terutama untuk akses data diluar lingkup radiologi yang memerlukan informasi terkait.

Bila dibandingkan dengan kondisi sebelum diimplementasikannya sistem PACS, workflow menjadi sedikit berbeda. Bila dilihat dari segi akses data yang dilakukan, dapat diilustrasikan pada gambar 2 yang dicontohkan pada salah satu penggunaan modalitas yaitu CR X-Ray konvensional.

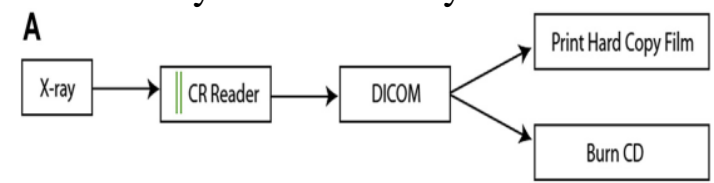

B

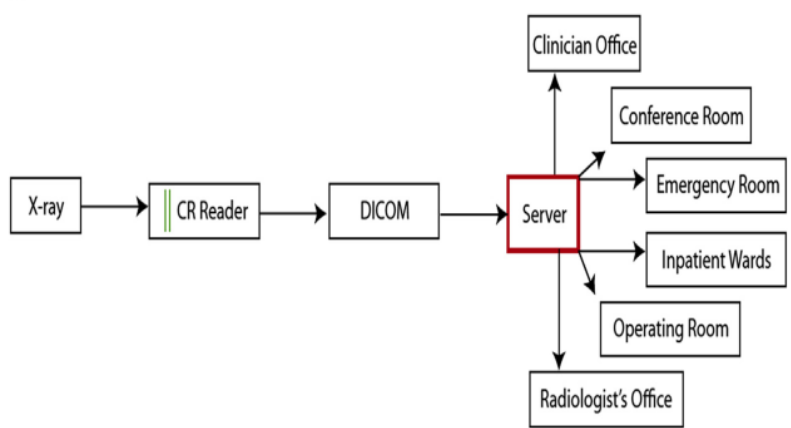

Gambar 2. Diagram akses output data pada dua sistem, tanpa PACS (A), dengan PACS

(B).

Perbandingan pelayanan radiologi menggunakan PACS dan tanpa menggunakan PACS dapat dilihat dari data output yang dihasilkan. Dengan menggunakan PACS, hasil citra radiologi dapat dilihat dari berbagai unit yang memerlukan informasi klinis.

PACS yang digunakan di RS Premier Bintaro sudah menerapkan HL7 Interface Server. HL7 Interface Server menyediakan interface communication antara sistem informasi yang ada dengan PACS (yaitu interface ke Sistem Informasi Rumah Sakit (SIRS) dan / atau Sistem Informasi Radiologi (RIS)). HL7 berkomunikasi dengan SIRS / RIS dengan menerima unsolicited messages atau pesan yang tidak diminta (biasanya HL7 atau DICOM) dari HIS / RIS dan mengubahnya menjadi prosedur tersimpan dalam SQL untuk PACS. 


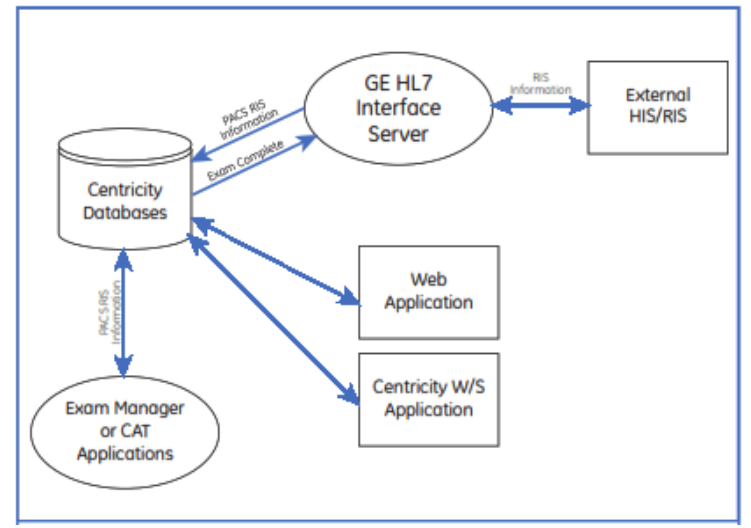

Gambar 3. Data Flow pada PACS dengan

HL7 Interface

Interface PACS pada HL7 di RS Premier Bintaro juga menyediakan fungsionalitas DICOM Modality Worklist (DMWL). Fungsi DMWL memungkinkan modalitas yang terhubung untuk "query" pada server HL7 mengenai demografi dan informasi urutan pemeriksaan yang diperoleh dari HIS / RIS. Informasi permintaan demografi dan jenis pemeriksaan kemudian tersedia secara lokal pada modalitas yang akan mengurangi kebutuhan untuk entri manual.

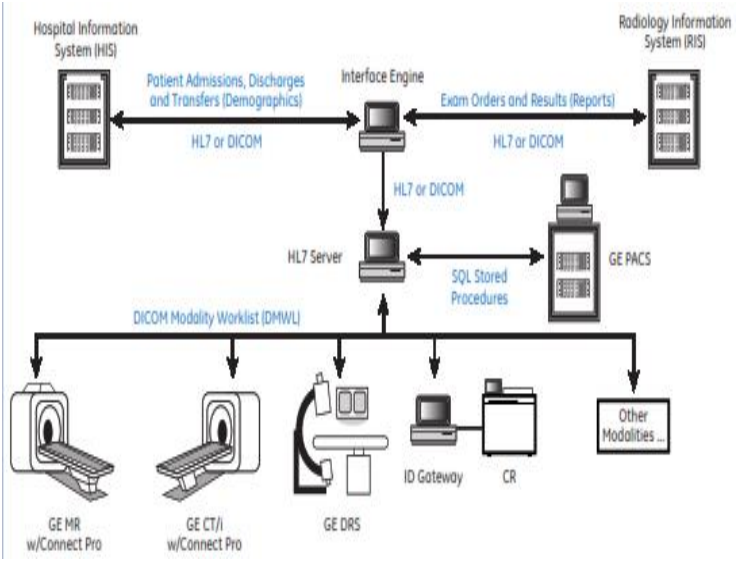

Gambar 4. Diagram server connection pada HL7 IS

\section{Kelebihan PACS}

Dengan diterapkannya PACS dalam instalasi radiologi RS Premier Bintaro, maka terdapat beberapa keuntungan yang diperoleh seperti mengurangi penggunaan film (Filmless), data dapat diakses kapan saja dan dimana saja, waktu pelayanan yang lebih singkat (memotong waktu tunggu printing film, waktu tunggu di radiologi, dan poli terkait), data tetap dalam bentuk digital (dapat dilakukan adjusting, editing, dan reformatting berulang), waktu penyimpanan lebih lama (pada server, waktu penghapusan/ pemusnahan data dapat diatur sesuai dengan kesepakatan), tidak memerlukan ruang arsip (Data disimpan dalam server), data yang diakses klien (dokter pengirim) dan server (radiografeer dan radiologist) dapat berupa data real time dengan bentuk 2D, 3D, sampai dengan CINE, data dapat diakses dalam waktu yang bersamaan oleh lebih dari satu orang (biasanya 25 user), dengen penerapan HL7 interface Server, input data pasien akan otomatis masuk dalam query, sehingga tidak ada overlapping data pasien (input manual) serta data dan riwayat pemeriksaan pasien diarsip dalam satu file induk dan dapat diakses dalam satu waktu.

\section{Kekurangan PACS}

Penerapan PACS dalam instalasi radiologi RS Premier Bintaro, dapat diketahui kekurangan yang terjadi seperti bergantung pada stabilitas koneksi, ketersediaan Sistem penunjang terkait (HIS dan RIS), invesment cost yang lumayan tinggi dibanding dengan sistem manual, bentuk data digital memungkinkan data mengalami kondisi "corrupt" akibat kesalahan sistem, serta sistem penyimpanan pada server akan mengakibatkan data bergantung pada kondisi storage.

\section{Tantangan Penggunaan PACS}

Hal yang menjadi dasar dan perhitungan dalam penerapan PACS dalam unit Radiologi adalah Stabilitas koneksi. Stabilitas koneksi menjadi salah satu kekurangan karena koneksi memegang peran penting dalam sistem PACS sebagai alat transport dari subsistem satu ke subsistem lainnya. Sehingga perhatian pada masalah koneksi akan dapat mengurangi kemungkinan permasalahan lain yang akan muncul.

Dalam penerapan PACS di RS Premier Bintaro, beberapa kendala yang masih muncul menjadi tantangan kedepan dalam penyempurnaan sistem yang diterapkan. Beberapa masalah yang sering muncul dalam keseharian penggunaan PACS di unit 
radiologi RS Premier Bintaro adalah mengenai stabilitas koneksi antar sistem, terutama pada saat data post processing pada modalitas / Advance Workstation (AW) dikirim untuk disimpan kedalam PACS.

Selain masalah teknis jaringan yang akan menghambat kerja sistem yang digunakan, tantangan lain yang timbul adalah edukasi user yang terkait langsung dengan penerapan PACS tersebut. Edukasi dianggap penting karena dengan data berbasis digital dan komputerisasi maka diperlukan kemampuan lebih dalam pengolahan, penyajian, serta penyampaian data terutama user yang terkait langsung dengan penyampaian informasi diagnostik pasien. Tantangan berikutnya perlu dilakukan pengukuran lebih lanjut terkait dengan keuntungan dari investasi yang diperoleh dari implementasi PACS.

\section{Keberhasilan Implementasi PACS}

Keberhasilan implementasi atau penerapan PACS di RS Premier Bintaro tidak terlepas dari aspek kualitas sistem yang diberikan. Pengguna PACS merasa sistem tersebut mudah untuk dipahami dan mudah untuk digunakan. Pemanfaatan PACS mampu meningkatkan kepercayaan diri petugas radiologi sehingga mampu meningkatkan kinerja dan produktivitasnya.

Produktivitas dan akurasi dari interpretasi dokter spesialis radiologi akan meningkat apabila interface dari sistem mampu mengotomasi alur kerja manual yang memakan waktu relatif lebih lama. Akurasi interpretasi dapat ditingkatkan dengan menggunakan PACS sehingga membantu dalam proses pemberian keputusan dokter untuk menata ulang proses yang kompleks dalam menginterpretasikan gambar dan penalaran diagnostik.

Penggunaan PACS di RS Premier Bintaro mampu meningkatkan mutu rumah sakit dengan mempercepat waktu pelayanan di instalasi radiologi, hal tersebut dapat dilihat dari perbandingan lama waktu tunggu pelayanan radiologi sebelum dan sesudah diimplementasikannya PACS. Penerapan PACS sangat dirasakan oleh pengguna khususnya dokter dan tenaga radiologi karena mampu mempercepat proses penanganan pasien, tidak diperlukan lagi penggunaan kertas dan CD untuk keperluan pengarsipan. PACS juga mampu membantu dokter radiologi dalam mendiagnosa, merawat serta memberikan penanganan medis ke tahap selanjutnya sehingga lama tinggal pasien untuk perawatan (length of stay) pasien dapat diturunkan dan biaya perawatan yang dikeluarkan oleh pasien dapat diminimalisir.

Pemanfaatan PACS mampu
meningkatkan respon time pelayanan radiologi berdampak pula pada penurunan tingkat infeksi nosokomial dari sesama pasien, pasien ke petugas. Penerapan PACS di Instalasi Radiologi RS Premier Bintaro dapat memberikan hubungan kompetitif dimana pasien merasa puas dengan pelayanan yang diberikan. Manfaat lain yang bisa dirasakan dari penerapan PACS yaitu waktu pengarsipan data medis elektronik jauh lebih lama dimana data tersebut dapat diakses kapan saja dan dimana saja oleh karena data tersimpan di dalam server. Apabila dilihat dari potensial investasi, penerapan PACS cenderung memberikan peningkatan permintaan pelayanan radiologi, dengan meningkatnya permintaan pelayanan radiologi di RS Premier Bintaro akan mampu meningkatkan pendapatan rumah sakit.

\section{KESIMPULAN}

Penerapan PACS dalam Instalasi Radiologi RS Premier Bintaro memberikan keuntungan dalam pelayanan serta meningkatkan efektifitas dan efisiensi dalam hal komunikasi data, pengarsipan, serta waktu pelayanan. Kekurangan PACS yang memungkinkan terganggunya sistem PACS menjadi tantangan besar untuk menyempurnakan penerapan PACS dan harus menjadi perhatian khususnya pada stabilitas koneksi dan edukasi pengguna sistem.

\section{UCAPAN TERIMA KASIH}

Peneliti mengucapkan terimakasih kepada RS Premier Bintaro yang telah memberikan kesempatan untuk melakukan penelitian ini. 


\section{DAFTAR PUSTAKA}

1. Anonim. Readiness S. GE Site Planning guide. 2005.

2. Bogdan, O., Alin, C., Aurel, V., \& Serban, M. (2008). Integrated medical system using DICOM and HL7 standards, (January 1988).

3. Carison KS Tong, Eric TT Wong. Governance of Picture Archiving and Communications Systems: Data Security and Quality Management of Filmless Radiology. New York: Hershey: Medical Information Science Reference; 2009.

4. Creighton, C. (1999). A Literature Review on Communication Between Picture Archiving and Communication Systems and Radiology Information Systems and/or Hospital Information Systems, 138-143.

5. Chandratilleke MHoneybul S. Modifying Clinicians Use of PACS Imaging. Journal of Digital Imaging. 2013;26(6):1008-12

6. Duyck P, Pynoo B, Devolder P, Voet T, Adang L, Ovaere D, et al. Monitoring the PACS implementation process in a large university hospital-discrepancies between radiologists and physicians. $J$ Digit Imaging. 2010;23(1):73-80.

7. Erimalata S, Program Magister Akuntansi, Universitas Mataram. Pendekatan Hot-Fit Framework dalam Generalized Structural Component Analysis pada Sistem Informasi Manajemen Barang Milik Daerah: Sebuah Pengujian Efek Resiprokal. J Akunt Dan Investasi. 2016;17(2):141-57

8. G. Koutelakis, G. Trianatafyllou, G. Mandellos, M.Koukias, and D. Lymperopoulos, "A Web Portal that Supports PACS Applications Based on WADO Service of DICOM Standard, "WSEAS Trans. Inf.Sci. Appl.,Vol. 2, No. 12, pp.2107-2114, 2005.

9. Huang, H.K, 2004. PACS and Imaging Informatics. Hongkong: John Willey and Sons,Inc.
10. Instrumentation $M$, Technological $T$, Agiou A, Str S. Implementation of a simulated Radiology DICOM-PACS network. 2014;(January 2004).

11. Jorwekar G, Dandekar K, Baviskar P. Picture Archiving and Communication System (PACS): Clinician's Perspective About Filmless Imaging. Indian Journal of Surgery. 2013;77(S3):774-7

12. Keith J. Dreyer, David S Hirschorn, Thrall JH, Mehta A. PACS: A Guide to the Digital Revolution. Second. New York: Springer Science+Business Media, Inc; 2006.

13. Kinsey, T. V, \& Lewis, E. (2000). Interfacing the PACS and the HIS : Results of a 5-year Implementa-, 8001, 883-891.

14. Le, Anh H.T., 2009. Integration of Computeraided Diagnosis/Detection (CAD) Result in PACS Environment Using CAD-PACS toolkit and DICOM SR. USA

15. Lewis TE, Horton MC, Kinsey TV, Shelton PD. Acceptance Testing of Integrated Picture Archiving and Communications System. J.Digit Imaging 1999; 12:163-5.

16. Lingamallu, K., \& Nayakvadi, S. (2017). Role of HIS and RIS in Improving Quality of Patient, 9(7), 725-734.

17. Miyasaka K. Picture Archiving and Communication System. Kokyu To Junkan. 1989;37:845-51.

18. Song JW, Mango MC, Museru LM, Kesselman A, Foryoung K, Kiloloma O, et al. Successful Implementation of a PACS in Tanzania. J Am Coll Radiol. 2017;14(5):710-10.

19. Suwarsa, Iwan Iga, 2009. Implementasi Open Source Picture Archiving and Communication System untuk Pengelolaan Citra Medis. Surabaya: Jurusan Teknik Elektro ITS.

20. Zhang W, Gutierrez O. Understanding Information Technology Acceptance in the Social Sectore. 2005;6 